\title{
DYEABILITY OF TEXTILE FIBRES WITH AZO COMPOUNDS PREPARED BY COUPLING RED ONION SKIN EXTRACT WITH DIAZONIUM SALTS
}

\author{
O. AKARANTA" and D.E. EFANGA
}

Department of Pure and Industrial Chemistry, University of Port Harcourt, Port Harcourt, Nigeria.

(Received: 22 September 1995; accepted: 04 April 1997)

\begin{abstract}
Several azo compounds were prepared using red onion skin extract as a coupling component. The azo compounds were formed in-situ in cotton fabrics as azo dyes and applied to polyester fabrics as disperse dyes. They were found to produce not very bright colours on cotton fabrics but brilliant colours on polyester fabrics. The wash fastness tests showed that the azo compounds on cotton fabrics have fastness of 1-2, while most of the dyeings on polyester fabrics have fastness of 3-4 on the grey scale. The results also showed that the substituent group in the benzene nucleus of the diazonium salts have effects on the chemical (acid and alkali) fastness properties of the azo compounds.
\end{abstract}

Key words: Azo compounds, dyeing, onion skin, textile fibres.

\section{INTRODUCTION}

Many types of azo compounds widely used for dyeing textiles are largely based on chemicals derived from petroleum sources. The emergence of diazotization reaction offers a basis for developments in the field of azo compounds. Odozi et al. ${ }^{1}$ reported that red onion skin extract consists of quercetin, kaempferol, galangin, fisetin and apigenin. These compounds, being phenolic in nature, could undergo the well known coupling reaction with diazonium salts, as with $\beta$-naphthol in the formation of azo dyes. Other agricultural wastes reported to have phenolic components similar to those of red onion skin include peanut skin ${ }^{2}$ and coconut coir dust, ${ }^{3}$ and their aqueous extracts have been used in the production of surface coating resins. ${ }^{4 \cdot 7}$ These agricultural wastes are readily available in tropical countries in millions of tonnes per annum at little cost.

In view of the overall shortage of synthetic phenols, it was thought desirable to investigate the possibility of substituting naphthols and other benzene nucleus compounds with red onion skin extract, a renewable resource, in the preparation of azo dyes. This will augment the chemical feedstock requirements of some industries in developing countries. The objective of the study was to investigate the dyeability of textile fibres with azo compounds prepared by coupling red onion skin extract with diazonium salts. 


\section{METHODS AND MATERIALS}

Red onion skin extract: Air dried red onion skin was extracted with distilled water using the method described by Odozi et al. ${ }^{8}$ Solid extract was obtained from the extract solution by evaporating the solvent, under reduced pressure, using a rotor evaporator. The method gives a yield of $36 \%$ solid extract.

Coupling of the extract: The red onion skin extract $(80 \mathrm{~g})$ was dissolved in $120 \mathrm{ml}$ of $2 \mathrm{M} \mathrm{NaOH}$ solution. This solution was used as the coupling component. Eighty millilitres $(80 \mathrm{ml})$ of aniline diazonium salt solution prepared using a standard method ${ }^{9}$ was poured slowly, with stirring, into a beaker containing the coupling component solution and allowed to stand in an ice-bath for $30 \mathrm{~min}$ while yellow crystals of the azo compound formed. The crystals were filtered, washed with distilled water and dried at $40^{\circ} \mathrm{C}$ in a vacuum oven. An average of $96.8 \mathrm{~g}$ of the red onion skin extract - aniline azo compound were obtained. The same procedure was used for the preparation of the other red onion skin extract azo compounds.

Application of the azo compounds as azo dyes: One gram samples of bleached cotton fabrics, obtained from Kaduna Textile (Nig) Ltd., were first treated with hot distilled water for $15 \mathrm{~min}$ to remove residual fillers. Each sample was then impregnated with an alkaline red onion skin extract solution, squeezed and dried to avoid uneven shades. The impregnated fabric was transferred to a solution of aniline diazonium salt with the azo compound forming in-situ in the fabric, dyeing the bleached cotton fabric to a yellow shade. Unreacted red onion skin extract and surface colours were washed off with an alkaline soap solution, prepared by dissolving $5.0 \mathrm{~g}$ of bone dry Omo detergent in a litre of warm water, rinsed with cold water until wash water was colourless and then dried at room temperature.

Application of the azo compounds as disperse dyes: A stock solution (1\%w/v) of each azo compound was prepared by pasting $1.0 \mathrm{~g}$ of the compound with $0.3 \mathrm{~g}$ of Omo detergent, then dissolved in $100 \mathrm{ml}$ of hot water and strained. Two millilitres $(2 \mathrm{ml})$ of $10 \% \mathrm{v} / \mathrm{v}$ aqueous solution of benzyl alcohol was used as a carrier in the aqueous dyeing, while $2 \mathrm{ml}$ of $0.50 \% \mathrm{w} / \mathrm{v}$ aqueous solution of Omo detergent was used as the dispersing agent. The dyebath was set at $95^{\circ} \mathrm{C}$ and the $1 \mathrm{~g}$ polyester fabrics, obtained from Nichemtex Industries (Nig.) Ltd., Lagos, dyed for $60 \mathrm{~min}$ in a liquor ratio of 100:1. The dyed fabrics were rinsed in cold water, squeezed and dried. It was observed that dyeing the polyester fabrics without the carrier (benzyl alcohol) showed no reasonable uptake of the azo compounds even at boil.

Fastness tests: Solutions of the azo compounds were prepared by dissolving $0.01 \mathrm{~g}$ of each compound in $2 \mathrm{ml}$ acetone. To each of the azo compound solution $(0.5 \mathrm{ml})$, $2 \mathrm{ml}$ distilled water was added and used as a reference sample. Acetone solution 
$(0.5 \mathrm{ml})$ of each azo compound was used for acid and alkali fastness tests. The dyeings on the cotton and polyester fabrics were subjected to International Standards Organization (ISO) washing tests, ${ }^{10}$ using a liquor ratio of 50:1.

\section{RESULTS AND DISCUSSION}

The designation, components and percentage yields of the azo compounds are given in Table 1. The IR spectra of the red onion skin extract ${ }^{1}$ and its azo-metal complexes ${ }^{11}$ have been reported elsewhere. The melting points, colours/shades and fastriess tests results of the azo compounds are given in Tables 2 and 3.

Table 1: Designation, components and percentage yields of the azo compounds.

\begin{tabular}{lcllc}
\hline Designation & $\begin{array}{c}\text { Coupling } \\
\text { component }\end{array}$ & $\begin{array}{c}\text { Type of diazonium } \\
\text { salt }\end{array}$ & $\begin{array}{c}\text { Substituent } \\
\text { group }\end{array}$ & $\begin{array}{c}\text { Yield } \\
(\%)\end{array}$ \\
\hline A1 & $\begin{array}{c}\text { Red onion } \\
\text { skin extract }\end{array}$ & Aniline & - & 92.4 \\
A2 & $"$ & 2-nitroaniline & $-\mathrm{NO}_{2}$ (ortho) & 78.3 \\
A3 & $"$ & 4-nitroaniline & $-\mathrm{NO}_{2}$ (para) & 79.8 \\
A4 & $"$. & 4-aminophenol & $-\mathrm{OH}$ & 90.7 \\
A5 & $"$ & 2-methylaniline & $-\mathrm{CH}_{3}$ (ortho) & 86.9 \\
A6 & $"$ & 4-methylaniline & $-\mathrm{CH}_{3}$ (para) & 89.6 \\
A7 & & 4-aminobenzoic & $-\mathrm{COOH}$ & 88.2 \\
& & acid & & \\
\hline
\end{tabular}

Table 2: Characteristics of the azo compound.

\begin{tabular}{cccccccc}
\hline \multirow{2}{*}{$\begin{array}{c}\text { Azo dye } \\
\text { designation }\end{array}$} & $\begin{array}{c}\text { Mass tone } \\
\text { colour }\end{array}$ & $\begin{array}{c}\mathrm{mp} \\
{ }^{\circ} \mathrm{C}\end{array}$ & & \multicolumn{5}{l}{ Shade in } \\
\cline { 5 - 8 } & & & $\begin{array}{c}\text { Distilled } \\
\text { water }\end{array}$ & $\mathrm{H}_{2} \mathrm{SO}_{4}$ & $5 \%$ & $\mathrm{NaOH}$ & $\mathrm{Na}_{2} \mathrm{CO}_{3}$ \\
& & & & & $5 \%$ & $5 \%$ \\
$\mathrm{~A} 1$ & $\mathrm{YE}$ & $68-70$ & $\mathrm{YE}$ & $\mathrm{YE}$ & $\mathrm{YE}$ & $\mathrm{YE}$ \\
$\mathrm{A} 2$ & $\mathrm{OR}$ & $87-89$ & $\mathrm{OR}$ & $\mathrm{OR}$ & $\mathrm{OR}$ & $\mathrm{OR}$ \\
$\mathrm{A} 3$ & $\mathrm{OR}$ & $92-94$ & $\mathrm{OR}$ & $\mathrm{OR}$ & $\mathrm{PK}$ & $\mathrm{PK}$ \\
$\mathrm{A} 4$ & $\mathrm{BL}$ & $90-92$ & $\mathrm{BR}$ & $\mathrm{BR}$ & $\mathrm{VL}$ & $\mathrm{VL}$ \\
$\mathrm{A} 5$ & $\mathrm{BR}$ & $110-112$ & $\mathrm{BR}$ & $\mathrm{BR}$ & $\mathrm{BR}$ & $\mathrm{BR}$ \\
$\mathrm{A} 6$ & $\mathrm{BR}$ & $88-90$ & $\mathrm{BR}$ & $\mathrm{BR}$ & $\mathrm{BR}$ & $\mathrm{BR}$ \\
$\mathrm{A} 7$ & $\mathrm{BR}$ & $156-157$ & $\mathrm{BR}$ & $\mathrm{BR}$ & $\mathrm{BR}$ & $\mathrm{BR}$ \\
\hline
\end{tabular}

$\mathrm{YE}=$ Yellow, $\mathrm{OR}=$ Orange, $\mathrm{BL}=$ Black, $\mathrm{BR}=$ Brown, $\mathrm{PK}=$ Pink, $\mathrm{VL}=$ Violet. 
Table 3: Shades and wash fastness properties of the azo compounds in fabrics.

\begin{tabular}{cccc}
\hline $\begin{array}{l}\text { Azo dye } \\
\text { designation }\end{array}$ & Fabric & Shade & Wash fastness \\
\hline \multirow{2}{*}{ A1 } & COF & YE & $1-2$ \\
$\vdots$ & PEF & OR & $3-4$ \\
A2 & COF & YB & $2-3$ \\
& PEF & PK & $2-3$ \\
A3 & COF & YB & DFC \\
& PEF & PK & DFC \\
A4 & COF & BB & DFC \\
A5 & PEF & VL & DFC \\
& COF & BR & $1-2$ \\
A6 & PEF & YE & $3-4$ \\
& COF & BR & $1-2$ \\
A7 & PEF & YE & $2-3$ \\
& COF & PK & $2-3$ \\
& PEF & PK & $2-3$ \\
\hline
\end{tabular}

$\mathrm{COF}=$ Cotton fabric, $\mathrm{PEF}=$ Polyester fabric, $\mathrm{DFC}=$ Dyed fabric changed colour in alkaline solution, $\mathrm{YB}=$ Yellowish Brown, $\mathrm{BB}=$ Bluish-Black .

The azo compounds did not have sharp melting points. This may be due to the fact that red onion skin extract contains a mixture of phenolic compounds (flavonoids), all of which are capable of undergoing coupling reactions with a diazonium salt. The resultant product of each coupling reaction carried out in this study, therefore, is a mixture of azo compounds, hence exhibited a broad melting point.

The various diazonium salts gave a range of colours in the cotton fabrics with the coupling component, red onion skin extract. The dyeing of the azo compounds on polyester fabrics gave different colours from those obtained by forming the azo compounds in-situ in cotton fabrics. The colours of the azo compounds were not very bright on cotton fabrics. This may be due to the possibility of the various flavonoids in the red onion skin extract coupling with the diazonium salt in-situ in the cotton fabric to give what appeared as.a single colour. The dyeing on polyester fabrics gave brilliant colours. This may be attributed to the polyester fibre absorbing from the mixture of the azo compounds of each coupling reaction, the azo compound with the greatest affinity for it. This could be called selective absorption. 
In the acid and alkali fastness tests, the colour changes relative to the colours of the reference samples were noted as shown in Table 2. From the results, azo compounds A1, A2, A5, A6 and A7 are fast to acid and alkali media. The position and type of the substituent group in the benzene nucleus of the diazonium salt appear to be important factors towards the chemical fastness properties of the azo compounds. The electron withdrawing substituents at the ortho position tend to enhance the alkali and acid fastness properties of the azo compounds prepared in this study. However, no significant differences exist regarding the position of the electron donating substituents in respect of acid and alkali fastness.

All the azo compounds on cotton fabrics have wash fastness of 1-2 on the grey scale, except A3 and A4 which were sensitive (unstable) in alkaline solutions as shown in Table 3 . The azo compounds on polyester fabrics have wash fastness properties of 3-4 particularly those of aniline and 2-methylaniline diazonium salts. The azo compound of 4-aminobenzoic acid, 4-methylaniline and 2nitroaniline were found to be suitable for dyeing polyester fabrics. However, the azo compounds of aniline and 2-methylaniline diazonium salts were the most suitable for dyeing polyester fibres based on the brightness of the colours, chemical fastness and their wash fastness properties.

The results are generally encouraging, considering the fact that red onion skin, a bioresource, has the potential of being a raw material for the preparation of azo dyes. This provides another opportunity for the utilization of red onion skin and other agricultural wastes of similar chemical compositions.

\section{References}

1. Odozi T.O., Akaranta O. \& Agiri G.O. (1984). Some chemical features of red onion skin extract: a tanning material. Journal of Leather Research 2(1): 10-17.

2. Stansbury M.F, Field E.T. \& Guthrie J.D. (1950). Tannin and related pigments in the red skins of peanuts. Journal of American Oil Chemists' Society 27: 317-319.

3. Tuason A.M. \& Reyes A.t. (1959). Water soluble extract from coconut husk and its application in leather technology. Philippine Journal of Science 88: $253-256$.

4. Chen C.M. (1982). Effects of formaldehyde concentration on the bond quality of peanut hull extract copolymer resins. Industrial and Engineering Chemistry Products Research and Development 21: 450-457. 
5. Akaranta O., Donbebe W. \& Odozi T.O. (1996). Plywood adhesives based on red onion skin extract modified with cashewnut shell liquid. Bioresource Technology 56: 279-280.

6. Akaranta O. (1996). Wood finishes from modified coconut coir dust extract. Pigment and Resin Technology 25(5): 11-15.

7. Akaranta O. \& Wankasi D. (1996). Effects of Kaolin clay on the bond quality of coconut coir dust tannin-formaldehyde based wood adhesives. Journal of the National Science Council of Sri Lanka 24(2):127-132.

8. Odozi T.O; Akaranta O. \& Ogban I.U. (1985). Development of wood varnishes from palm fruit fibre hydroxylate and red onion skin tannin extract. Journal of Oil and Colour Chemists' Association 68(4): 94-97.

9. Vogel A.I. (1956). A Textbook of practical organic chemistry. 3rd ed. Longmans, Green \& Co. Ltd., London. pp. 590.

10. Standard methods for the determination of the colour fastness of textiles (1978). The Society of Dyers and Colourists, 4 th ed. Bradford.

11. Akaranta O. \& Odozi T.O. (1985). Azo-metal complexes from red onion skin tannin extract condensation products. Journal of Leather Research 3(4): 82-88. 